\title{
Mobile Apps sebagai Penunjang Kegiatan Urban Agriculture di Kota
}

\section{Bandung}

\author{
Vika Adriati Praditriyani', \\ Dr. Dwinita Larasati, $\mathrm{MA}^{2}$, \\ Drs. Alfonzo Ronald Kopaha, M.Sn \\ ${ }^{1}$ Program Studi Magister Desain Institut Teknologi Bandung \\ 2,3Fakultas Seni Rupa dan Desain Institut Teknologi Bandung \\ Email: vika.adriati@gmail.com
}

\begin{abstract}
Abstrak. Setiap kota memiliki porsi lahan hijau masing-masing yang dapat ditentukan oleh luas wilayahnya. Masyarakat urban yang tinggal di kota harusnya memiliki peran dalam pelestarian lahan hijau. Namun, masyarakat belum dapat memahami manfaat, kegunaan dan cara mengaplikasikannya. Hal tersebut menjadi dasar penelitian yang berhubungan dengan peran teknologi sebagai alat bantu dalam menjembatani kegiatan yang berupaya melestarikan lahan hijau, salah satunya dengan kegiatan urban agriculture. Penelitian ini menggunakan responden suatu komunitas di kota Bandung yang berumur 18 -30 tahun yang memiliki minat dan orientasi terhadap lingkungan, yaitu BdgBerkebun. Alat bantu yang digunakan memiliki konten tentang konsep urban agriculture, cara memanfaatkan lahan sempit menjadi lahan hijau yang produktif serta informasi-informasi seputar tanaman dan pemeliharaannya. Penelitian ini menghasilkan sebuah rancangan aplikasi perawatan tanaman dengan menampilkan simulasi kebun virtual dan dilengkapi dengan fitur scheduling dan reminder. Setelah rancangan ini diuji coba, hasilnya menunjukkan bahwa sebagian besar pengguna merasa terbantu dan membutuhkan suatu media digital yang bersifat fleksibel dalam memaksimalkan kegiatan urban agriculture di wilayah kota.
\end{abstract}

Kata Kunci : Aplikasi Mobile, Lahan Hijau, Urban agriculture.

\begin{abstract}
Green spaces in the city can be determined from total city area. The citizens should have a role in the preservation of green spaces. However, the citizens have not been able to understand the benefits, uses, and how to apply it in their own spaces. Therefore, it is necessary to develop a supportive media to assist an urban agriculture activity, which is bridging technology and activities that proposed to preserve green spaces. This study uses a 18-30 years old respondents in a community, called BdgBerkebun in Bandung city who have an interest and orientation to the environment. The assistive media must have the content of urban agriculture concept, how to turn the narrow land into green productive spaces and about the plant information and its maintenance. The study is to produce an application to perform treatment plant with the virtual simulation gardening with the scheduling and a reminder feature. The results after design is tested are showed that most users feel
\end{abstract}


helped and require a digital media which is more flexible in urban agriculture activities in the city.

Keywords : Green Spaces, Mobile Application, Urban agriculture.

\section{Pendahuluan}

Daerah perkotaan yang merupakan pusat dari semua bidang dan kegiatan, seperti pusat perkantoran, perdagangan, dan transportasi. Kegiatan-kegiatan tersebut menjadi ciri-ciri kemajuan dan kemegahan yang seluruhnya terjadi di kota. Berbeda dengan pertanian atau berkebun, kegiatan tersebut erat kaitannya dengan wilayah pedesaan. Berdasarkan analisis data pertumbuhan penduduk, populasi Kota Bandung meningkat sebesar 2,7\% pertahun. Menurut data tersebut, Kota Bandung mengalami perubahan fungsi lahan agriculture menjadi lahan non-agriculture. Peningkatan ruang terbuka hijau merupakan salah satu upaya meningkatkan lahan agriculture di wilayah kota, namun di Kota Bandung hanya memiliki kurang lebih 13\% dari $30 \%$ target idealnya.

Kesadaran dan keinginan masyarakat untuk menciptakan lahan hijau masih kurang, selain itu birokrasi dan kurangnya lahan di daerah perkotaan juga menjadi masalah yang menghambat. Menciptakan solusi untuk wilayah kota atas berbagai masalah kota yang timbul seperti polusi, banjir, pemanasan global, pembangunan gedunggedung atau perumahan, urbanisasi, dan lain sebagainya, yaitu dengan menciptakan dan menjadikan urban agriculture sebagai kebiasaan atau gaya hidup yang tidak hanya memberi dampak positif kepada masyarakat namun juga sebagai sarana pendukung untuk mencapai kota yang berkelanjutan dengan masyarakat yang berwawasan lingkungan. Karena kegiatan urban agriculture ini tidak semata-mata menggunakan lahan kosong, namun juga diperlukan rencana agar dapat berlangsung dalam jangka yang panjang. Jarang sekali melihat masyarakat urban (kota) dengan mobilitasnya yang sangat tinggi menyempatkan dirinya untuk bercocok-tanam atau berkebun. Secara teori memang sangat mudah untuk membuat masyarakat bergerak untuk menciptakan urban argriculture seperti bertani (urban farming) atau berkebun (urban gardening), namun ternyata implementasinya tidak semudah yang dibayangkan. Walaupun sulit untuk menciptakan pertanian di wilayah kota, urban agriculture mempunyai peran penting bagi kota untuk membangun kota yang berkelanjutan. Urban agriculture memiliki banyak fungsi :

1. Fungsi Bio-Ecological : Menambah lahan hijau, sebagai pengatur iklim mikro, penyedia oksigen, menyerap air hujan dan polusi.

2. Fungsi Sosial, Ekonomi dan Budaya : Sebagai media penyalur komunikasi masyarakat, penyedia ruang rekreasi publik, penyedia ruang untuk pembelajaran dan penelitian.

3. Fungsi Estetis : Mempercantik pemandangan untuk menstimulasi kreatifitas dan produktifitas.

4. Fungsi Ekologis kota. 
Oleh karena itu diperlukan kegiatan urban agriculture sebagai trigger untuk mencapai target ideal ruang hijau serta memulihkan kondisi lingkungan dari efek pembangunan. Kota Bandung memiliki komunitas yang fokus pada lingkungan dan telah bekerjasama dengan pemerintah untuk membimbing masyarakat untuk membiasakan diri dalam kegiatan urban agriculture. Tujuannya untuk meningkatkan kesadaran masyarakat tentang kondisi lingkungan dan menawarkan solusi yang kreatif, modern serta menyenangkan.

Pendekatan media interaksi yang bersifat digital dalam menunjang urban agriculture untuk membantu mengoptimalisasi lahan hijau untuk mencapai kota berkelanjutan dapat dijadikan suatu solusi. Media digital yang digunakan yaitu berupa mobile apps yang dapat membentuk suatu komunitas sosial dan memberikan pengetahuan serta pengalaman dalam urban agriculture yang menarik.

\section{$2 \quad$ Metode}

Metode yang digunakan dalam penelitian ini adalah metode kualitatif, karena tujuannya memahami fenomena sosial melalui gambaran holistik dan memperbanyak pemahaman mendalam. Selain itu juga metode ini digunakan untuk menjelaskan bagaimana mobile apps sebagai media interaktif dapat membantu dalam kegiatan urban agriculture.

\section{Definisi Urban Agriculture}

Food and Agriculture Organization of the United Nation (FAO), telah mendefinisikan urban agriculture sebagai sebuah industri yang memproduksi, proses dan memasarkan makanan dan bahan bakar, terutama dalam menanggapi permintaan harian konsumen dalam kota, kota, atau metropolis, di darat dan air tersebar di seluruh daerah perkotaan dan pinggiran kota, menerapkan metode produksi yang intensif, menggunakan dan menggunakan kembali sumber daya alam dan limbah perkotaan untuk menghasilkan keragaman tanaman dan ternak.

Council on Agriculture, Science and Technology mendefinisikan urban agriculture mencakup aspek kesehatan lingkungan, perbaikan dan rekreasi. Pertanian perkotaan adalah sistem yang kompleks yang mencakup spektrum minat, dari inti tradisional kegiatan yang berhubungan dengan produksi, pengolahan, pemasaran, distribusi dan konsumsi, untuk manfaat berkembang biak dan layanan lain yang kurang diakui dan didokumentasikan secara meluas. Ini termasuk rekreasi dan bersantai; vitalitas ekonomi dan kewirausahaan bisnis, kesehatan individu dan kesejahteraan; kesehatan masyarakat dan kesejahteraan; keindahan lingkungan; dan pemulihan lingkungan dan remediasi.

Urban agriculture merupakan kegiatan yang menguntungkan bagi kota. Ada banyak manfaat yang bisa diambil dari kegiatan ini, tidak hanya pada sektor lingkungan, tetapi juga pada sektor-sektor lain seperti ekonomi, sosial, kesehatan, dan sektor lainnya. Urban agriculture bukanlah kegiatan yang individual, tetapi juga digunakan 
sebagai kegiatan publik dengan mendistribusikan produk, baik mentah atau sudah diolah. Hasil dari urban agriculture sebagai pemenuhan kebutuhan konsumen, terutama di daerah perkotaan, karena sebagian besar kegiatan pertanian yang dilakukan di daerah pedesaan atau pinggiran kota. Jika warga terus bergantung pada sumber daya alam yang dihasilkan masyarakat pedesaan, akan ada permintaan yang sangat tinggi untuk sumber daya alam karena permintaan warga akan meningkat seiring kebutuhan mereka. Urban agriculture diperlukan, tidak hanya untuk menyediakan kebutuhan warga, tetapi juga untuk memberikan rasa nyaman dan relaks pada pikiran mereka dengan bentuk lain dari urban agriculture, seperti taman komunitas (community garden) atau taman tematik. Taman atau kebun dibuat di daerah perkotaan untuk membantu melestarikan lingkungan dan memberikan manfaat bagi warga yang tinggal di sekitarnya, seperti penghilang stres, memberikan sarana dan prasarana untuk kegiatan warga, dan lain-lain. Oleh karena itu kegiatan pertanian perkotaan tidak hanya tentang pertanian atau berkebun, tetapi juga proses pemenuhan kebutuhan masyarakat, baik secara fisik dan mental. Urban agriculture perlu diadakan di daerah perkotaan, untuk membantu warga mendapatkan lingkungan yang lebih baik dan membantu meringankan kebutuhan yang melonjak.

\section{$4 \quad$ Urban agriculture Secara Konvensional atau Digital}

Kegiatan urban agriculture dapat dilakukan dengan cara bertani dan berkebun di daerah perkotaan. Dengan menanam sayuran, buah, tanaman, dan rempah-rempah atau tanaman lain untuk konsumsi masyarakat, pertanian dan aktivitas berkebun membantu dalam pelestarian lingkungan. Namun, kurangnya lahan untuk urban agriculture dapat menjadi penghalang untuk melakukan kegiatan ini. Jika pertanian perkotaan memiliki manfaat tambahan jika diimplementasikan, seperti masyarakat dapat menjadi penyedia makanan lokal dan menciptakan komunitas lokal.

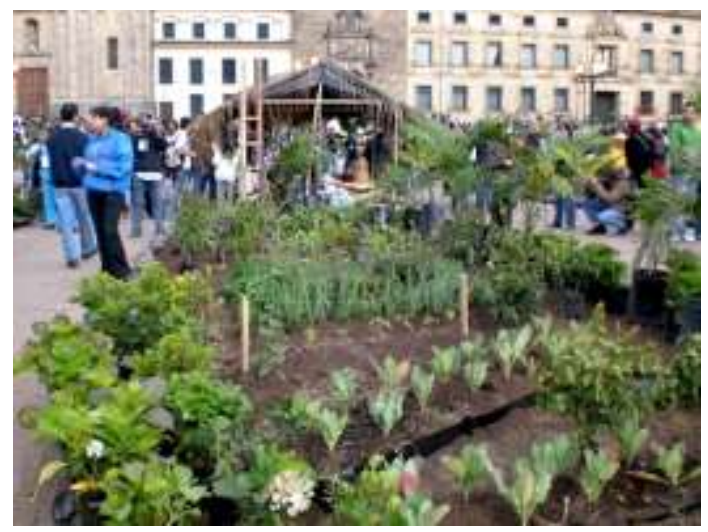

Gambar 1 : Urban agriculture di Kota New York Sumber : http://www.nationalgeographic.com (23 Juli 2014) 
Warga masih kurang menyadari tentang keuntungan urban agriculture, hal itu terjadi karena mereka masih kurang mampu untuk mengelola dan memelihara lingkungan sekitar mereka, terutama lingkungan hijau. Sebagian besar warga masih berorientasi ekonomi, di mana pembangunan pusat perbelanjaan, perkantoran, dan perumahan yang lebih diutamakan. Dengan pemikiran masyarakat yang seperti ini, permasalahan lingkungan semakin terpinggirkan. Akibatnya, lahan-lahan yang berpotensi sebagai ruang terbuka hijau, lahan bertani dan berkebun semakin habis digantikan oleh bangunan-bangunan megah.

Padatnya penduduk di daerah perkotaan, baik akibat urbanisasi maupun tingginya angka kelahiran menyebabkan sempit dan sesaknya daerah kota dan munculnya pemukiman-pemukiman penduduk yang baru. Hampir semua lahan kosong dijadikan tempat tinggal sedangkan lahan-lahan terbuka hijau hampir tidak terlihat. Tidak adanya celah untuk kegiatan urban agriculture mengurungkan minat masyarakat untuk membenahi lingkungan.

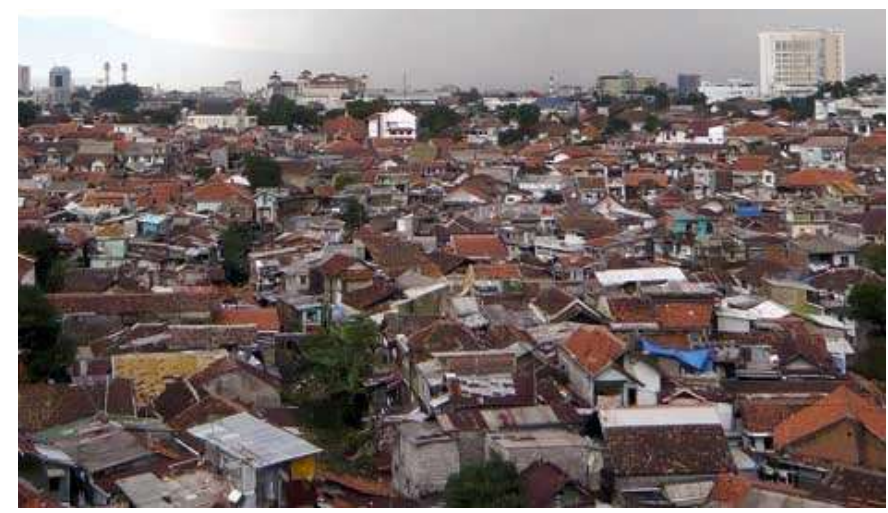

Gambar 2: Pemukiman Padat Penduduk Kota Bandung Sumber: http://www.newspaper.pikiran-rakyat.com (13 Juli 2014)

Urban agriculture menggunakan cara konvensional yaitu dengan bercocok tanam, masyarakat dapat mengerjakannya secara individu tanpa tergabung dengan komunitas. Sistem konvensional yaitu dengan menanam sendiri pada lahan pekarangan yang dimiliki. Dalam hal ini masyarakat dapat mengimplementasikan urban argriculture dengan cara membuat vertical garden, rooftop garden dan lainlain. Cara-cara ini dapat dengan mudah diaplikasikan di rumah, baik dengan lahan yang luas maupun dengan lahan yang sempit. Cara ini merupakan sebuah tindak lanjut dari pemahaman masyarakat terhadap urban agriculture. Urban agriculture diharapkan menggugah masyarakat untuk lebih peduli terhadap lingkungan.

Kota Bandung memiliki beberapa komunitas masyarakat yang memiliki orientasi pada lingkungan hidup, BdgBerkebun (Bandung Berkebun) merupakan salah satunya. Mereka menggunakan metode konvensional dengan memanfaatkan lahan tidur atau kosong yang telah disetujui oleh pemerintah dan masyarakat setempat untuk 
digunakan sebagai ladang hijau. Anggota masyarakat yang terbagi menjadi beberapa kelompok dan ditempatkan di beberapa wilayah kota. Anggota komunitas ini adalah relawan yang bekerja secara sukarela dalam rangka untuk mengajak masyarakat dan membuat Bandung sebagai kota yang berorientasi lingkungan. Mereka menanam berbagai jenis sayuran atau buah-buahan dengan peserta mulai dari anak-anak sampai dengan orang dewasa. Komunitas ini membantu program pemerintah untuk menciptakan kegiatan urban agriculture dengan cara berkebun di wilayah kota. Mereka memberikan informasi dan mengajarkan tentang urban agriculture dan pelaksanaannya kepada masyarakat.

Menanam tanaman adalah salah satu cara lain untuk menunjukkan betapa anda peduli dengan lingkungan dengan cara yang sederhana atau hanya bergerak untuk mengatur, menggunakan kembali dan mendaur ulang sampah untuk menyelamatkan lingkungan. Hal ini akan menjadi lebih baik jika anda dapat menggunakan kembali sampah perkotaan sebagai bahan penyimpanan untuk berkebun.

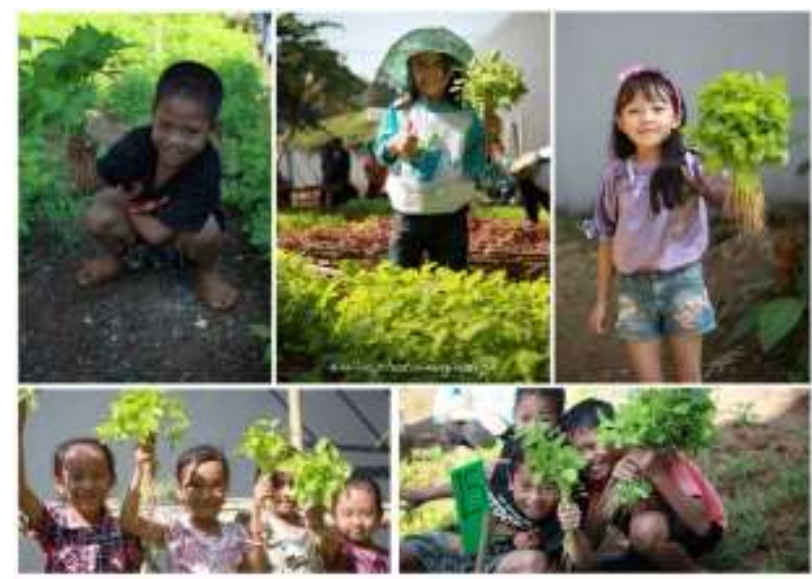

Gambar 3 : Kegiatan Berkebun oleh Komunitas BdgBerkebun Sumber : http://www.green.kompasiana.com (02 Agustus 2014)

Permasalahan masyarakat terutama di kota yaitu mobilitasnya yang sangat tinggi dan kurang memungkinkan untuk berkebun dan bersosialisasi dengan secara bertatap muka. Pada dasarnya, masyarakat gemar bersosialisasi dan berkumpul. Urban agriculture dapat menggabungkan masyarakat dan membentuk suatu komunitas sosial. Selain itu tanaman yang ditanam perlu perawatan secara intensif dan periodik. Oleh karena itu masyarakat menggunakan media digital untuk mengatasi maslahmasalah tersebut. Adanya smartphone dan mobile apps dapat menjembatani masyarakat dalam pemeliharaan tanaman dan komunikasi antar masyarakat. Melalui media tersebut masyarakat menjadi lebih dekat dan lebih mudah mendapat informasi melalui mobile apps. 


\section{$5 \quad$ Mobile Application dan Urban agriculture}

Mobile Apps sebagai media digital interaktif akan sangat membantu bagi pengguna terutama masyarakat kota karena memungkinkan mereka untuk merawat tanaman dengan mudah. Merawat tanaman sekarang tidak hanya dapat dilakukan dengan kontak langsung dengan tanaman, tetapi juga dapat dilakukan di tempat yang berbeda, sehingga user tidak perlu khawatir jika dibiarkan tanaman dengan waktu yang lama. Dengan aplikasi mobile user dapat mengontrol dan memantau tanaman mudah. Berbeda dengan cara konvensional, tanaman akan mati jika user tidak merawat secara berkelanjutan seperti melakukan penyiraman, pemupukan, atau pemangkasan. Kegiatan urban agriculture dapat didukung secara penuh oleh aplikasi mobile. Melalui aplikasi mobile, keuntungan yang dapat diperoleh dengan (user) masyarakat:

1. Pengguna akan tertarik, mencari tahu, mengerti, dan langsung bergerak untuk memulai menanam tanaman dengan mudah, baik di lahan umum atau lahan pribadi.

2. Sebuah sistem database dan sistem pembagian waktu akan menjadi bagian dari aplikasi mobile. Aplikasi mobile dapat dengan mudah mengontrol, memantau dan merencanakan perkembangan sebuah tanaman yang ditanam melalui aplikasi mobile dan itu adalah cara untuk mendapatkan hasil yang lebih baik pada berkebun.

3. Pengguna (user) pada dasarnya adalah makhluk sosial, mereka dapat menggunakan fungsi sosial pada aplikasi mobile untuk berkomunikasi dengan mengumpulkan masyarakat pada forum sesuai dengan kegiatan urban agriculture. Semakin banyak orang bergabung pada forum atau komunitas ini, berarti semakin banyak orang yang peduli dan kemudian bergerak memelihara lingkungan perkotaan.

4. Sistem point reward akan diberlakukan dan menarik minat orang-orang tentang urban argriculture melalui aplikasi mobile.

5. Sistem sharing pada aplikasi mobile akan membantu pengguna untuk berbagi informasi dengan orang lain. Berbagi perkembangan, gambar atau informasi tentang tanaman atau berkebun di wilayah kota.

6. Mengingat gaya hidup, media digital dapat menciptakan urban agriculture sebagai tren untuk menciptakan lingkungan yang hijau dan kota yang berkelanjutan. 
Dalam hal ini, ada beberapa interaksi yang terjadi:

1. Mobile Apps dengan Pengguna. Mobile apps menjadi media untuk mengingatkan user jadwal untuk perawatan seperti penyiraman, pemupukan, pemindahan tanaman ke dalam pot yang baru atau media lain .

2. Pengguna dengan tanaman. Pengguna dapat langsung berinteraksi dengan tanaman mereka. Memelihara tanaman, dari penanaman sampai dengan waktu panen.

3. Mobile apps dapat membuat interaksi dengan obyek yang ditanam dengan dukungan sensor, sehingga tanaman dapat mengontrol dan memantau dengan pengguna dari jauh.

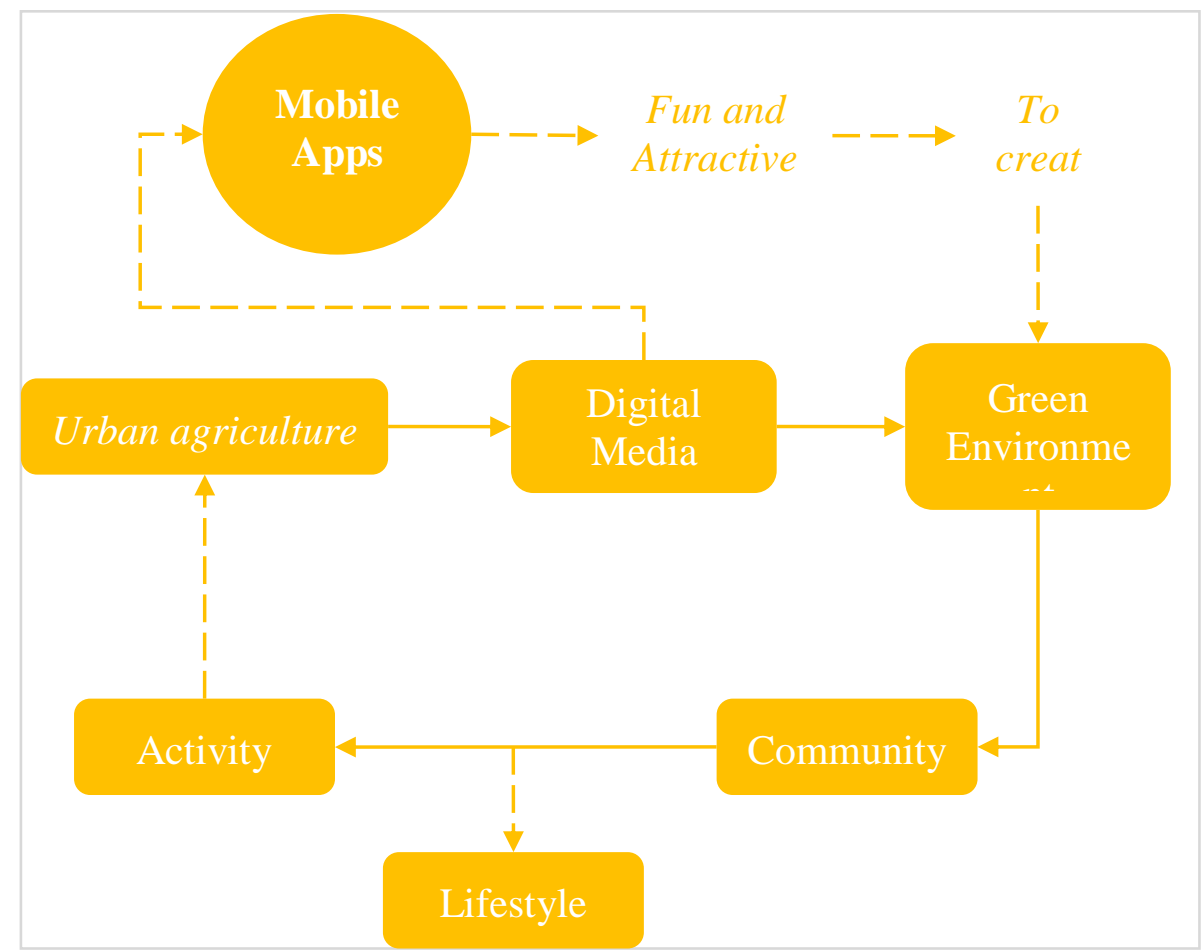

Gambar 4: Diagram korelasi antara Mobile Apps dan urban agriculture Sumber: Pribadi, 23 Juli 2014

Pemilihan tampilan visual dalam mobile apps merupakan syarat penting dalam pengenalan urban agriculture dalam masyarakat. Gaya flat design memiliki penekanan pada kegunaan dan elemen yang bersih agar mengurangi distraksi. Gambar yang sederhana dapat menyampaikan pesan dan memiliki waktu memuat lebih cepat. Warna cerah dan kontras yang digunakan membuat ilustrasi atau ikon menarik perhatian. Dengan gaya flat design ini, pengguna akan mendapatkan 
pengalaman yang berbeda dengan simplifikasi dari tanaman dan ikon tanaman yang unik. Simplifikasi tanaman tidak hanya berdiri sendiri, namun dengan bantuan fotofoto pendukung, pengguna akan lebih jelas dalam mendapatkan informasi dan edukasi tentang berbagai macam tanaman yang dapat tumbuh di wilayah kota.

Urban agriculture dalam mobile apps tidak hanya digunakan untuk kepentingan pribadi atau kelompok, namun dapat digunakan secara meluas dengan menjadikannya sebuah kampanye dalam pelestarian lingkungan. Dengan menggunakan teori "A-A Procedure" yang dijabarkan menjadi Attention (perhatian), Interest (minat), Desire (keinginan), dan Action (tindakan) (Sadjiman, 2006: 12-13), diharapkan dapat menggugah keinginan pengguna serta melakukan kegiatan urban agriculture di wilayah perkotaan.
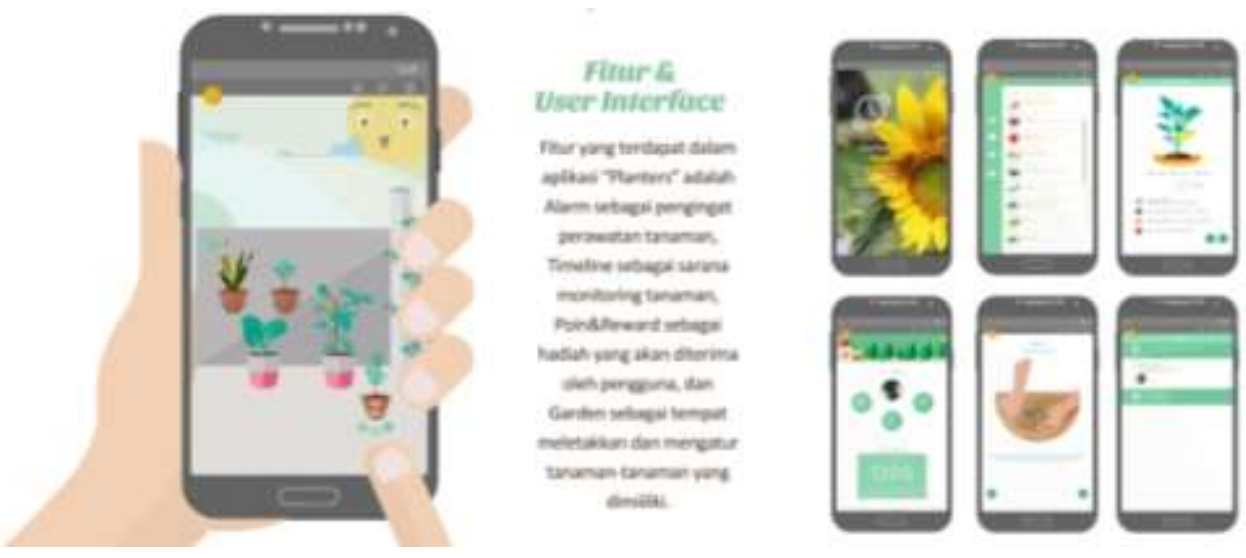

Gambar 5 : Mobile apps urban gardening

Sumber : Penulis, 23 Januari 2014

Untuk menguji efektifitas media digital berupa mobile apps ini, penulis mengadakan post-test sebagai tahapan dalam menentukan kelebihan dan kekurangannya. Posttest dilakukan pada target pengguna yaitu masyarakat umum dan komunitas. Jumlah target pengguna yang melakukan post-test berjumlah 12 orang. Dan hasil post-test menyatakan bahwa sebagian besar target pengguna yang mengikuti uji coba menilai aplikasi memiliki tingkat efektifitas yang cukup mendukung dan informatif terhadap kegiatan urban agriculture. Selain itu tanggapan target pengguna terhadap gaya desain dan visualisasi yang digunakan yaitu aplikasi "Planters" memiliki visual yang bagus dan unik. Namun, 6 dari 12 orang pengguna mengeluhkan kesulitan yang dihadapinya pada saat menjalani uji coba, yaitu sebanyak 3 orang pengguna kesulitan karena tidak adanya penjelasan icon yang digunakan, 2 orang pengguna kesulitan terhadap bahasa yang digunakan (bahasa Indonesia dan bahasa Inggris), dan 1 orang pengguna kesulitan mencari icon atau tombol untuk sharing ke dalam media sosial. 


\section{Kesimpulan}

Mobile apps mempunyai kontribusi terhadap urban agriculture yaitu dengan mengumpulkan dan menyatukan komunitas untuk membangun masyarakat berbasis lingkungan terutama di Kota Bandung. Selain itu, mobile apps juga menunjang kegiatan bercocok tanam yaitu dengan cara mengawasi, memantau, dan merencanakan tanaman yang ditanam melalui media digital. Dengan kemudahan yang diberikan oleh media digital diharapkan masyarakat tertarik dan mulai menyelesaikan permasalahan lingkungan melalui urban agriculture. Mobile apps bukan merupakan pemisah antara cara konvensional dan cara digital, tetapi mobile apps membantu dalam proses urban agriculture secara konvensional agar mempunyai hasil yang optimal. Namun dukungan, komitmen, dan aksi tidak hanya dari masyarakat tetapi juga dari berbagai stakeholder yang berkaitan dengan bidang tersebut.

\section{$7 \quad$ Referensi}

Butler, L. and D.M. Monorek (eds). 2002. Urban agriculture Communities : Opportunities for Common Ground. Ames, Lowa : Council For Agricultural Science And Technology.

Hadinata D, Christian \& Sugiyantoro. Kebijakan Perlindungan Lahan Pertanian dan

Alih Fungsi Lahan Pertanian di Kabupaten Bandung. Jurnal Perencanaan Wilayah dan Kota Bandung SAPPK V2N2.

Informasi Laporan Penyelenggaraan Pemerintahan Daerah (ILPPD) Data, Kota Bandung 2012.

Lynch, K. 1960. The Image Of The City. MIT Pres Cabridge.

Purnomohadi, N. 2006. Ruang Terbuka Hijau Sebagai Unsur Utama Tata Ruang Kota. Direktorat Jenderal Penataan Ruang, Departemen Pekerjaan Umum.

Smit, J., Rattu, A., \& Nasr, J. 1996 : Urban agriculture: Food, Jobs and Sustainable Cities, Publication Series for Habitat II, Volume One, New York: UNDP. Wiryono. 2013. Pengantar Ilmu Lingkungan. Pertelon Media : Bengkulu. 